\title{
Educational Leadership and ICT Implementation in Israeli Arab Sector - towards a Model of Hybrid Leadership
}

\author{
Suleiman HABIBALLAH ${ }^{1}$ \\ Nicolae BIBU ${ }^{2}$ \\ Doina DANAIATA ${ }^{3}$
}

\begin{abstract}
The present article discusses the concept of hybrid leadership in the context of the educational leadership in ICT implementation in Israeli Arab sector. In the Arab sector in Israel, where the school system has always been patriarchal, authoritarian, and strictly hierarchical, developing a hybrid school leadership represents a particularly interesting, important and beneficial challenge. The discussion evolves from analyzing the qualitative findings obtained from interviews conducted with 12 stakeholders: principals, teachers, ICT coordinators and external coordinators. The analysis and interpretation of the findings brought to introducing of the "hybrid model" of educational leadership that includes four components: (1) hybridity as open-minded thinking; (2) hybridity as proficiency at managing e-spaces and blended environments; (3) hybridity as openness to multiple databases of knowledge and multidisciplinary thinking; (4) hybridity as communal responsibility.
\end{abstract}

Keywords: hybrid leadership, educational digital leadership, ICT reform implementation, principal-as-ICT-leader.

JEL classification: I00, I29, P46

DOI: $10.24818 / \mathrm{RMCI}$.2021.1.74

\section{Introduction}

In the context of the $21^{\text {st }}$ century, featured by swift dynamics of change and shifting concepts and paradigms, the concept of leadership also undergoes constant changes and adaptation to new demands and inquiries. The dramatic shift that occurred in school leadership worldwide in the context of the ICT reform and implementation brought about a need for an eclectic form of leadership, which can combine and wisely use various forms of leadership, with consideration for cultural varieties and variances, as well as for continuously changing demands. The principal-as-ICT-leader works in multiple administrative, managerial, organizational, and learning environments, which cross the boundaries of time, space, and disciplinary frameworks; all that poses new challenges, as well as a

1 Habiballah Suleiman, West University of Timisoara, Romania, E-mail: swakhaled@ gmail.com, Telephone: +972552272488, Fax: +97246468233

2 Bibu Nicolae, West University of Timisoara, Romania, E-mail: nicolae.bibu@euvt.ro.com

3 Danaiata Doina, West University of Timisoara, Romania, E-mail: doina.danaiata@euvt.ro

74 Review of International Comparative Management

Volume 22, Issue 1, March 2021 
need for developing new competencies of leadership in the context of blended teaching, learning, and managing.

The principal's educational leadership was defined as the key factor for the existence of an optimal educational climate which provides opportunity for teachers to operate effective teaching processes leading to meaningful learning as much as possible (e.g. Elmore, 2008). The survey administered to 30 principals in Tehran, Iran found "a strong positive correlation between educational leadership and computer use" (Afshari et al., 2009). The educational leadership behavior, along with reward behavior and intellectual stimulation significantly affected the teachers' level of satisfaction from communication.

The educational leadership style of principals, along with cultural perception were found of significant contribution to the extent of computer use by principals themselves (Arokiasamy, Abdullah \& Ismail, 2014). Educational leadership practices positively affected teachers' perceptions on integrating ICT in teaching $(\mathrm{Ng}, 2008)$. Eight dimensions of educational leadership style were included in Ng's survey: "developing shared vision, building consensus, individualized support, intellectual stimulation, modeling behavior, high performance expectation, strengthening school culture and building collaborative structure" (Ng, 2008).

Among the questions that emerge before the research and practice of educational leadership: how does a 21st century principal-as-ICT-leader transmit her/his enthusiasm and inspiration through the virtual space and enables her/his followers' intellectual and professional development? What are the characteristics of e-interaction in blended managerial and teaching/learning environments that make a successful principal-as-ICT-leader? What is the new definition of school vision in the blended spaces and how is it conveyed to and implemented by the working staff?

We consider that in today's schools, educational leaders underwent a digital metamorphosis and became what we address as "hybrid leaders". An extensive body of research has consistently shown that enhancing communication and collaboration in ICT school leadership requires hybrid modes of content based and personalized professional development, learning resources, peers' support, and digital evaluation. Thus, the first section of the article describes the notion of hybrid leadership in the educational digital context, including its characteristics and main components.

The second section of the article is subdivided into two parts: the first subsection addresses the vicissitudes of the Arab educational leadership in Israel while the second subsection describes the qualitative findings of our recent study on the subject, whose interpretation foregrounds the model of hybrid educational leadership presented in the first section.

\section{Hybrid leadership}

The notion of hybridity was first mentioned by Gronn (2010a; 2010b, 2011) in his research on leadership: he described hybridity as a complementarity of various approaches and forms, as opposed to binary approach. The concept of

Review of International Comparative Management

Volume 22, Issue 1, March 2021 
hybrid leadership was introduced to undertake a revision of the notion of distributed leadership. It refers to the perspective on leadership from a variety of diverse viewpoints, which, as we argue, describes more accurately the complexity of educational technological leadership.

The hybrid leadership is generated and informed by various leadership styles. Those styles are both embedded in and borrowed from both global and individual cultural contexts. The hybridity signifies reworking the relationship between two existing, usually opposed, categories, combining and re-connecting their attributes, coming up with a hybrid form.

Hybridization performs blending between hierarchical and heterarchical modes of responsibilities and relations. The hybridity subverts the "black \& white" conceptualization and by introducing diversity and gradation. It involves the ability to hold a number of complementary qualities that either are opposed to each other, or belong to different cultural and social frameworks; to combine two systems of beliefs that are not always consistent, and also to act accordingly, with a necessary degree of responsiveness and responsibility.

We address the hybridity of school leadership in ICT implementation according to the following criteria: (1) hybridity as open-minded thinking; (2) hybridity as proficiency at managing e-spaces and blended environments; (3) hybridity as openness to multiple databases of knowledge and multidisciplinary thinking; (4) hybridity as communal responsibility.

\section{a. Hybridity as open-minded thinking}

The principal as hybrid leader should be able to combine and maneuver between various modes of thinking and cultural paradigms: she/he should be able to integrate between patriarchic and hierarchic modes of thinking, instructional way of managing, and encouraging initiatives from middle-to-low range workers, being sensitive and available to her/his workers and their needs. The hybrid educational leader is especially responsive to cultural and social contexts; her/his mind is open to both multi-cultural perspectives of the 21 st century learning and unique national local interests and characteristics. The hybrid leader thinks and acts in the framework that is beyond narrow political perspectives, but still reveals sensitivity and faithfulness to the local cultures. Principals who are responsible and effective have the capability to create a professionally and personally warm and nurturing environment for teachers, learners, and community with parents to enable collaboration for common improvement. The hybrid leadership, defined as "technology leadership" by Saudi scholars, should be in harmony with collective culture and the vision of quality education.

The effective principal with hybrid characteristics is multi-tasking: she/he simultaneously performs two managerial/administrative functions and builds cultural ties, establishing behavioral norms, rituals, and symbols, as a part of school culture and vision. She/he navigates among different clusters of structures, tools, and routines of school culture, teachers; involvement, and leadership behaviors, considering how knowledge and understanding are constructed, how innovations 
penetrate and diffuse, and how to build adequate structures, tools, and routines to attain the desirable outcomes.

\section{b. Hybridity as managing e-space and blended environments: ICT proficiency}

The principal as hybrid leader should be highly proficient in everything related to digital literacy and competence, defined as those skills, knowledge, and attitudes that make learners use digital media for participation, work and problem solving, either independently or in collaboration with others, and do so in a critical, responsible, and creative manner.

The hybrid leader is able to orientate and interact successfully and efficiently with her/his staff through the ICT means of communication (via emailing, WhatsApp messages, blogs etc): the ability to communicate effectively using technology has been defined as one of the vital skills for the 21 st century principal. Other vital skills are: familiarity with and expertise in software and hardware, using information and data retrieval, planning and managing - the prerequisites for effective 21 st century leaders.

She/he also should be capable of managing assignments and updating in the e-space via learning digital platforms such as MOODLE, schoolie, i-contact, to name but a few. The familiarity with such notions as compatibility or replacement for software and hardware, to keep up with the constant changes in innovations; if unfamiliar with those notions, the principal may purchase obsolete and outdated technologies thereby using the funds ineffectively.

In other words, she/he should be able to "flow" within e-environments as skillfully as in non-virtual ones, that is, in the classroom; she/he should demonstrate full proficiency in managing digital communication at all levels. Indeed, the efficient and proficient e-communication was named among the most influential factors in promoting ICT assimilation in school culture.

\section{c. Hybridity as openness to multiple databases of knowledge}

The principal as hybrid leader should be well-versed in and open to various fields of knowledge, especially to distinct and often opposed versions, narratives, and points of view on controversial subjects. She/he should be proficient in multiple subjects and fields of study and have a multidisciplinary orientation. In the era of accountability, she/he is proficient in gathering and analyzing data, collecting and interpreting results and communicating findings in order to enhance instructional practices and increase productivity, using data in making leadership decisions.

The hybrid principal-as-ICT-leader is comprehensive, place-conscious, knowledgeable about policies and planning, but at the same time open to the individual needs, perceptions, and culture of stakeholders in the community. She/he is equally competent in funding sources and applying those funds for the technology programs, as well as in identifying which technologies are most effective on the school campus. 


\section{d. Hybridity as communal responsibility}

The hybridity is characterized by responsible leadership that consists in listening to the ideas and working together, applying the ideas such as small learning communities and collaborating with teachers to come up with new solutions to improve the student achievement. The hybridity in leadership is characterized by commitment to accountability, as well as by high level of social and communal involvement, as the principal-as-ICT-leader should assume both instructional and ethical responsibilities for managing the complexity of ties and relationships between school organization, communities, and stakeholders.

Often times the principal faces various dilemmas concerning the appropriateness of the digital communication in schools, taking into consideration not only positive but also potentially negative outcomes of students using cell phones, instant messaging or blogs, as well as the ways of mitigating those negative outcomes. It is up to the hybrid leader's discretion to assess and determine the educational values while deciding on instructional methods.

The principal as an ICT leader faces the complex mission of making ICT a part of school culture and a school a part of online community. Thus, as a main leader of change, $\mathrm{s} / \mathrm{h}$ is required to make a double change, or, rather a double transformation: she/he has both to undergo a transformation him/herself in the online reality and to become able to inspire a further transformation in others.

The matrix in Figure 1 illustrates the components of the Hybrid Leadership: (1) hybridity as open-minded thinking; (2) hybridity as proficiency at managing e-spaces and blended environments; (3) hybridity as openness to multiple databases of knowledge and multidisciplinary thinking; (4) hybridity as communal responsibility.

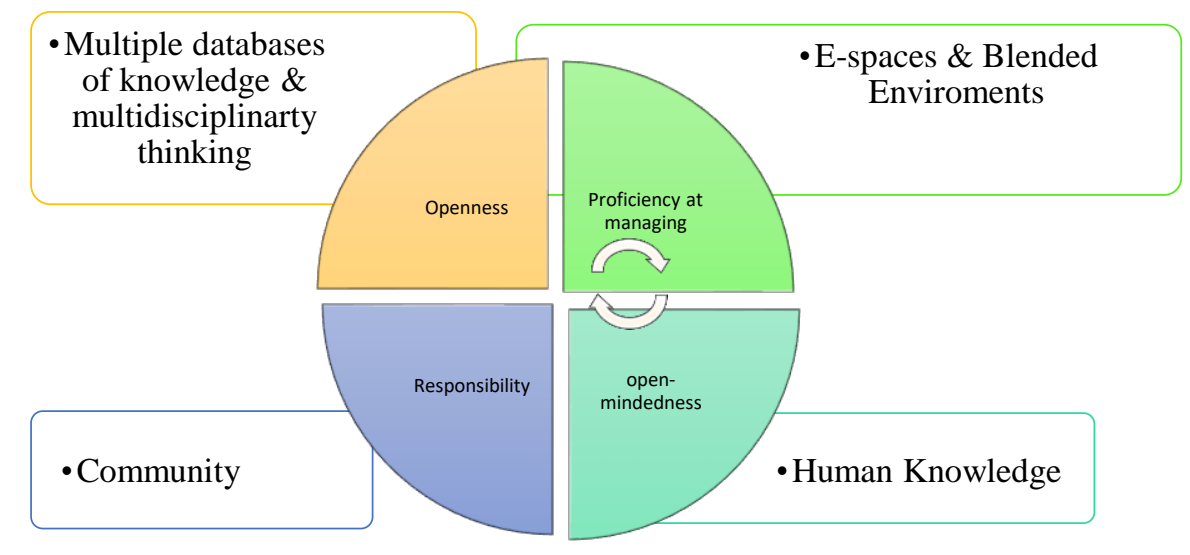

Figure 1. The components of Hybrid leadership (adapted from Gronn, 2011) 


\section{Hybrid educational leadership in Israeli Arab Sector}

\section{a. Educational ICT leadership in Arab sector - backgrounds}

In the context of ICT reform, which demands openness to changes, flexibility, and distributing the authority among multiple leaders operating outside and inside the digital networks, there is an ongoing tension between perceiving ICT as a symbol of change and the traditional character of Arab education system. These two conflictive forces - seeking for innovation versus preserving traditional structures and methods - generate complex and dynamic tensions within the schools (Forkosh-Baruch, Mioduser, \& Nachmias, 2012).

The principal in the Arab sector is on the junction of contrasting but coexisting circumstances, such as social and economic disparities between two sectors, along with special efforts by the Ministry of Education to improve the conditions of Arabic-speaking schools in Israel, as far as ICT reform is concerned. There are multiple tensions amidst other changes: cultural, social, economic, and political between the forces of resistance to change and the irreversible social processes of transformation occurring the Israeli Arab society: defending traditional values and methods versus the processes of modernization and innovation.

In addition to the internal tensions of the Arab society, the new principalas-ICT-leader faces the challenges of Israel's multicultural diversity and political tensions. The principal-as-ICT-leader in the Arab sector of Israel education system needs to reveal high adaptive skills and flexibility, while at the same time maintaining the balance and possible harmony between diverse cultural and social contexts. This further highlights the need to adopt an eclectic model of educational leadership with hybrid qualities.

Throughout the years, Arab leadership in Israel has undergone dramatic changes: a new generation of leaders emerged as a consequence of sociological and political changes, featured by transformational style, more self-conscious, and much more competent and capable, as compared to the "old" leadership in the first decades of the State of Israel. This new generation is more representative of the socioeconomic and sociopolitical composition of Arab society and reflects the community's growing national consciousness. As a result, it is viewed as the community's legitimate representative, especially with regard to matters of collective identity.

The communal responsibility is of especial significance for the principalas-ICT-leader in the Arab sector, cementing the basics for successful collaboration through communal and parental engagement in the learning process. Despite the inequities in various areas of educational systems, the principals from the Arabicspeaking schools demonstrated highly positive attitude and pro-active position toward ICT, seeing it as high priority issue for their schools to reach their educational objectives and become change agents of the Arab society as a whole (Forkosh et al., 2012). 
Therefore, the findings of this research are of contribution and interest for the principal in the Arab sector schools. She/he has an opportunity to benefit from extensive research on successful ICT leadership conducted by scholars across the globe, including Western, Eastern, and Arab countries, developed and developing alike. Learning from the extant findings on the preferable styles of leadership in advancing ICT reform from the experiences of different countries enables the principal to develop a multi-faceted perspective on leadership and carry out the mission of integrating ICT into school organizational culture and pedagogical practices.

\section{b. The Research on the ICT school leadership - qualitative results}

The recent study we conducted in 20 elementary schools in Israeli Arab sector aimed at examining the process of implementing the ICT reform as a function of educational leadership. The study included 345 participants, principals, ICT coordinators and teachers, who filled in structured questionnaires on their attitudes towards the ICT reform and its integration into teaching and learning. The findings obtained suggest the principal who promotes ICT by decentralizing authority and increasing the level of teachers' accountability and autonomy leads to the most outstanding success in ICT implementation in the school; the finding further corroborates the extensive research on positive effects of distributed leadership on school effectiveness and improvement (e.g. Leithwood \& Jantzi, 2006).

However, as the comparative results of the Meitzav State Examination throughout the years demonstrated4, only five schools showed remarkable increase in grades. Even though the effect of the national ICT program was very strong in the first year of its operation, there was no overall significant improvement in the achievements of students in schools in the Arab sector. The t-test revealed that, in all five schools, the principals were particularly supportive and knowledgeable in ICT, while the teachers displayed high scores on attitudes, competence, and perceptions of the ICT contribution to learning.

Therefore, the impact of national ICT program on learning outcomes needed further examination and it was clear that the effectiveness of the ICT program does not operate in a vacuum but should rather be examined in conjunction with a wide range of factors and variables that may influence students' achievements. Thus, to reach a deeper understanding of the quantitative findings, we performed a triangulation with qualitative paradigm, by conducting 12 semistructured interviews with principals, teachers, ICT-coordinators, and ICT instructors.

Four prominent themes emerged throughout the qualitative analysis of categories and subcategories in the interviews. (1) the importance of clear vision in ICT implementation process; (2) the importance of sustainable infrastructure and accessibility of external resources, along with proper technical support, (3), and (4) the importance of hybrid leadership 
The interviewees added a valuable insight into the reality of ICT implementation and assimilation processes in schools, presenting a realistic picture of the situation in Arab schools in Israel. They also brought to light important aspects pertaining to the characteristics of principals' leadership style, most successful for ICT implementation: those aspects are: the outmost significance of clear vision that contains reference to clear outcomes and the means of achieving them; the outmost significance of principals' supportive attitudes towards teachers' professional development and training.

\section{i. The Importance of Vision}

Two ICT coordinators interviewed from schools with improvement in learning outcomes explicitly addressed the subject of a clearly expressed vision in the principals' agenda and viewed themselves as both an integral part and architects of that vision; the school ICT policies were described as well focused and clearly defined. The principals from the same schools, too, emphasized and detailed their particular focus on learning outcomes in their ICT implementation agenda. It is important to note that those principals were not particularly "transformational" in their general attitude and stressed the hierarchical framework of their leadership activities; it seemed that the clearly stated goals, along with the well-defined means for their achievement, which included improving learning outcomes, constituted the main contribution to the schools' success.

The findings are corroborated with the results obtained by several recent studies showing that principal were the least prepared for the Visionary Leadership (e.g. Gencer \& Samur, 2016; Hamzah et al., 2017). Furthermore, the findings are in accord with the extant research that demands a strategic ICT plan that sets clear goals and defines clear means to achieve them; the research also mentions the importance o a guiding policy providing teachers with a direction for ICT use, in order to achieve high learning outcomes (Vanderlinde et al., 2008; Vermeulen et al., 2015). Moreover, the findings reinforce the need for integrating various leadership elements to achieve optimal results (Day et al., 2016).

\section{ii. The Importance of Sustainable Infrastructure and Technical Support}

In accord with the previous studies, the availability of suitable resources, hardware and software, technical support were among the variables of immense contribution to the success of ICT implementation. Participants found the technical problems "frustrating" and "discouraging": the data confirm that both equipment and technical support are necessary conditions for the successful implementation of ICT in teaching practices (Venezky \& Davis, 2002). The scarcity of Internet resources and adequate infrastructure is particularly prominent in Israel's Arab Sector schools, constituting another reason for failure and source of frustration. 


\section{iii. The importance of continuous professional development and training}

The teachers interviewed expressed frustration about time-consuming activities relating to building materials, complained about lacking teaching units with clear instructions. The external instructors and principals, in their turn, noted that poor preparation and competence of teachers negatively affect the ICT assimilation and use. All the participants knew about ICT benefits and were positive about their use in teaching; however, there was a clear gap between the need and taking an action.

Though the teachers were generally motivated and positive about the ICT reform, some of them confessed to lacking proper competences and professional training to be more confident in implementing it in their teaching practice (Albugami \& Ahmed, 2015). Teachers' frustration due to time-consuming activities related to building teaching materials could be easily dispelled by providing necessary materials, such as teaching units, and adequate professional training.

The adequate training, coaching, and professional development of teachers for adopting and assimilating the ICT in teaching practices require an exposure to diverse models of online teaching, together with the acquisition of skills, essential for intelligent use of ICT (Goldstein et al., 2010). This exposure is a basic prerequisite for making teachers more enthusiastic about ICT and its potential benefits in teaching.

The interviewees' opinions correlated with the quantitative results showing that pedagogical knowledge and the level of ICT proficiency affect teachers' readiness to introduce technological changes in their work and subsequently their use of ICT in teaching strategies; the results are consistent with the previous studies (Shamir-Inbal \& Kali, 2011; Nachmias, Myodosar, \& ForkoshBaruch, 2009).

In accord with various studies, our findings confirm that prioritizing teachers' training and constant professional development is one of the major necessities and most essential foundation for improving the quality of teaching in general and for optimal assimilation of ICT in classrooms in particular (AvidavUnger \& Friedman, 2011; Olofsson, Lindberg, Fransson, \& Hauge, 2011). The teacher's digital competence and proficiency have come to be considered as national projects of competing on the global stage: several countries worldwide tighten the connections between schools and training institutions by re-designing the diverse teaching programs (Goldstein et al., 2010).

The rationale underlying the need for training teachers in ICT stems from the fact that ICT technology, when applied through a combination of socioconstructivist pedagogic rationale, enables the teacher to design activities that support independent learning, and also enables the student to experiment with building rich products and acquiring high-order thinking skills. To benefit from ICT integration in their teaching, teachers must integrate the technology into the 
classroom and school agenda, in the context of the curriculum and in accordance with school policy.

iv. The importance of Hybrid Leadership: Principals-as-ICT-leaders

It has been stated that the first responsibility in implementing ICT tools in classrooms belongs to the teacher (e.g. Albugami \& Ahmed, 2015). Our findings also indicate the essential role of teachers in successful assimilating of ICT programs in school (Halverson \& Smith, 2008; Melamed \& Salant, 2010; Kozma, 2010). However, the school's principal is the key individual that enables teachers to generate such activities by encouraging them and giving support to instill change motivation in teachers. Overall, as we assumed in the initial stage of the research, the findings indeed indicate the crucial importance and efficiency of principals' transformational leadership in assimilating ICT in school culture and in teaching: A principal with characteristics of a transformational leader is ICT competent and aware of the ICT benefits for education and school as organization. Having these two characteristics a principal in able, in turn, to inspire, motivate and affect his/her followers' attitudes and perception regarding ICT implementation.

Beyond testifying to advantages of transformational leadership style in leading ICT implementation in the school's teaching activities, our findings reinforce the need for further developing and adopting an eclectic approach to leadership style, by blending various patterns of leadership in the process of ICT implementation in school organizational culture and teaching (Blau \& ShamirInbal, 2017). In essence, the whole notion of leadership should be reconceptualized, viewing the 21st century school leadership as "e-leadership", a new concept that is still "under construction" (Jameson, 2013). In a global world, leadership behaviors, which are best for ICT assimilation, may differ from country to country, according to the cultural and social context, as well as individual teaching practices of each country (House et al., 2004).

\section{Conclusions}

In a society that is being fundamentally transformed by digital technologies, both principals and teachers face the huge and unprecedented task consisting of reinventing schools; and many of them feel overwhelmed by the mandate of integrating ICT in teaching. Schools are required to undergo a substantial change from institutions that are transferring knowledge into learning organizations. As a result, school administrators are increasingly assuming leadership responsibilities with little or even no previous training in unfamiliar areas.

The recent decade has witnessed considerable developments in Israel's educational policies, in the context of ICT reform. Because of the decentralization processes occurring in the public school system, teachers become much more involved in the educational policymaking, as compared to the past; with the increase in the number of Arab school graduates completing their higher education,

Review of International Comparative Management

Volume 22, Issue 1, March 2021 
the situation has changed significantly in the Arab sector, too. Several studies conducted among Arab pre-service teachers in Israel, reflected the change: the findings demonstrated the desire for intellectual growth, for developing creativity of thinking, increased moral satisfaction from working with children, and viewing teachers as inspirational leaders for their community, were among the major factors that affected motivations for choosing a teaching career.

As the qualitative findings of our study show, there is still much room for improvement; it is up to policy and decision-makers to invest into the development of educational leadership capital of the Arab sector. As the field picture lamentably reveals, learning in many elementary schools in the Arab sector still occurs by traditional methods used in the seventies of the last century. Most of those methods became outdated and obsolete longtime ago. The situation is unconceivable, given the positive attitude towards ICT reform in the Arab education system; the mastery of technological competencies and computer skills ought to become an integral part of teacher's qualifications.

In addition, more resources are urgently needed to establish both hardware and software school infrastructure and provide regular technical support to maintain and update it. The lack of sustainable infrastructure and proper support leads to increased Arab teachers' frustration and infrequent use of ICT in teaching practices. Teachers and ICT coordinators should receive incentives for productive outcomes of ICT use in order to increase their level of job satisfaction. Furthermore, the principal should allow them a larger sphere of action, with more autonomy and responsibility, as well as encourage them to develop, both professionally and personally.

It is precisely because of the patriarchal and authoritative nature of the Arab society, characterized by strict hierarchy and inflexible rules, that the Arab school principal-as-ICT-leader should adopt the perspective of hybridity in leading technological change. While preserving the social and cultural status quo, the principal-as-ICT-leader promotes the reform, encourages collaboration between school organization and community, acts as a personal example in ICT implementation and conveys a compelling vision to school staff and community.

\section{References}

1. Afshari, M., Bakar K. A., Luan W. S., Samah B. A., \& Fooi, F. S. (2009) Technology and school leadership, Technology. Pedagogy and Education, 18(2), 235-248.

2. Albugami, S., \& Ahmed, V. (2015). Success factors for ICT implementation in Saudi secondary schools: From the perspective of ICT directors, head teachers, teachers and students. International Journal of Education and Development using Information and Communication Technology (IJEDICT), 11(1), 36-54.

3. Arokiasamy, A., Abdullah, A., \& Ismail, A.B. (2014). Correlation between cultural perceptions, leadership style and ICT usage by school principals in Malaysia. The Turkish Online Journal of Educational Technology, 13(3), 27-40.

4. Avidav-Unger, A. Friedman, Y. (2011). Empowering Teachers, Essence and Examples. Jerusalem: Henrietta Szold Institute. 
5. Blau, I., \& Shamir-Inbal, T. (2017). Digital competences and long-term ICT integration in school culture: The perspective of elementary school leaders. Education and Information Technologies, 22(3), 769-787.

6. Day, C., Gu, Q., \& Sammons, P. (2016). The impact of leadership on student outcomes: How successful school leaders use transformational and instructional strategies to make a difference. Educational Administration Quarterly, 52(2), 221-258.

7. Elmore, R. (2008). Leadership as the practice of improvement. Improving school leadership (Vol. 2) - Case studies on system leadership. Paris: OECD publication

8. Forkosh-Baruch, A. F., Nachmias, R., \& Mioduser, D. (2012). ICT in Hebrew Speaking and Arabic Speaking Schools in Israel: Findings from SITES2006. $4^{\text {th }}$ IEA International Research Conference (IRC-2010), 15, 1-16.

9. Gencer, M. S., \& Samur, Y. (2016). Leadership styles and technology: Leadership competency level of educational leaders. Procedia-Social and Behavioral Sciences, 229, 226-233.

10. Goldstein, A., Hayllwool, A., aldmann, N., Zidane, W., Zelkowitz, T., Tessler, B. et al. (2010). The current situation of student teachers training in ICT at four teacher training colleges. In: Y. Eshet-Alkalay, A. Caspi, S. Eden, N. Gary, \& Y. Yair (Eds.), The Human Learner in Technological Age (pp. 47-56). Raanana, IL: Open University.

11. Gronn, P. (2010a). Leadership: its genealogy, configuration and trajectory. Journal of Educational Administration and History, 42(4), 405-435.

12. Gronn, P. (2010b). Where to Next for Educational Leadership? In T. Bush, L. Bell \& D. Middleton (Eds.), The Principles of Educational Leadership and Management. London: Sage.

13. Gronn, P. (2011). Hybrid configurations of leadership. The SAGE handbook of leadership, 2011, 437-454.

14. Hamzah, N., Ariffin, A., \& Hamid, H. (2017, August). Web-Based Learning Environment Based on Students' Needs. In IOP Conference Series: Materials Science and Engineering (Vol. 226, No. 1, p. 012196). IOP Publishing.

15. House, R. J., Hanges, P. J., Javidan, M., Dorfman, P. W., \& Gupta, V. (Eds.). (2004). Culture, leadership, and organizations: The GLOBE study of 62 societies. NY: Sage publications.

16. Jameson, J. (2013). E-leadership in higher education: The fifth "age" of educational technology research. British Journal of Educational Technology, 44(6), 889-915.

17. Kozma, R. B. (2010). ICT policies and educational transformation. Retrieved August 10, 2015 from http://www.unesco.org/new/fileadmin/MULTIMEDIA/HQ/ED/ICT /pdf/ICTpoliedtran.pdf.

18. Leithwood, K., \& Jantzi, D. (2006). Transformational school leadership for largescale reform: Effects on students, teachers and their classroom practices. School effectiveness and school improvement, 17(2), 201-227.

19. Melamed, U., \& Salant, A. (2010). $21^{\text {st }}$ Century Skills-Global Review. Tel Aviv: The MOFET Institute.

20. Nachmias, R., Mioduser, D., \& Forkosh-Baruch, A. (2009). Integration of ICT in Teaching Math and Science in Israel. Tel Aviv: Tel Aviv University, Ramot.

21. Ng, W. L. (2008). Transformational leadership and the integration of information and communications technology into teaching. The Asia-Pacific Education Researcher, $17(1), 1-14$ 
22. Olofsson, A. D., Lindberg, J. O., Fransson, G., \& Hauge, T. E. (2011). Uptake and use of digital technologies in primary and secondary schools-a thematic review of research. Nordic Journal of Digital Literacy, 6(04), 207-225.

23. Shamir-Inbal, T., \& Kali, Y. (2011). A systems model for the implementation of technology in the school culture. In: D. Chen \& G. Kurtz (Eds.), Technology, learning and instruction (pp. 371-400). Or-Yehuda: Publication of the Center for Academic Studies. (Hebrew)

24. Vanderlinde, R., van Braak, J., De Windt, V., Tondeur, J., Hermans, R., \& Sinnaeve, I. (2008). Technology curriculum and planning for technology in schools: the Flemish case. TechTrends, 52 ,23-26.

25. Venezky, R., \& Davis, C. (2001). Quo Vademus? The Transformation of Schooling in a Networked World. Draft Executive Summary of the OECD project, "ICT and the Quality of Learning". Paris: OECD.

26. Venezky, R.L., \& Davis, C. (2002). Que Vademus? The Transformation of Schooling in a Networked World. Research report. OECD/CERI, Version 8c, March, 2002.

27. Vermeulen, M., Van Acker, F., Kreijns, K., \& Van Buuren, H. (2015). Does transformational leadership encourage teachers' use of digital learning materials? Educational Management Administration \& Leadership, 43(6), 1006-1025. 